\title{
Levels of Major and Minor Elements in Some Commercial Fruit Juices Available in Serbia
}

\author{
Dragan S Velimirović ${ }^{\star *}$, Snežana S Mitić ${ }^{2}$ Snežana B Tošić ${ }^{2}$, Biljana M \\ Kaličanin ${ }^{1}$, Aleksandra N Pavlović ${ }^{2}$ and Milan N Mitić ${ }^{2}$ \\ ${ }^{1}$ Faculty of Medicine, Department of Pharmacy, ${ }^{2}$ Faculty of Sciences and Mathematics, Department of Chemistry, University of \\ Niš, Serbia
}

*For correspondence: Email: drvelimirovic@yahoo.com;:Tel: +381184226712

\begin{abstract}
Purpose: To evaluate the macro- and micro-nutrient elements of some commercially available fruit juices in Serbia.

Methods: Inductively coupled plasma optical emission spectrometry (ICP-OES) technique was employed for determination of the major and minor elements in samples of two different types of fruit juices - clear and cloudy.

Results: Among macro-nutrient elements, potassium $(K)$ had the highest content of $230.17 \mu \mathrm{g} / \mathrm{g}$ in samples of multivitamine cloudy juice. The content of $K$ was higher in cloudy fruit juices than in clear fruit juices. The content of iron, which is among the group of trace elements, ranged from 2.237 to $5.911 \mu \mathrm{g} / \mathrm{g}$ in clear juices and 3.55 to $10.05 \mu \mathrm{g} / \mathrm{g}$ in cloudy fruit juices. Other trace elements followed the descending order copper > zinc > nickel in terms of their content. The presence of aluminum and cadmium in the tested samples of fruit juices can be toxic since they have no nutritional value, and hence may be treated as potential contaminants in these beverages.

Conclusion: All the tested juices had some nutritional value for human health and the juices could be use as an additional source of these elements. The content of aluminium and cadmium are below levels permitted by national regulations.
\end{abstract}

Keywords: Elements, Fruit juice, Inductively-coupled plasma optical emission spectrometry.

Tropical Journal of Pharmaceutical Research is indexed by Science Citation Index (SciSearch), Scopus, International Pharmaceutical Abstract, Chemical Abstracts, Embase, Index Copernicus, EBSCO, African Index Medicus, JournalSeek, Journal Citation Reports/Science Edition, Directory of Open Access Journals (DOAJ), African Journal Online, Bioline International, Open-J-Gate and Pharmacy Abstracts

\section{INTRODUCTION}

Approximately 30 elements are recognized to be essential for life. Whereas some of them such as $\mathrm{Ca}, \mathrm{K}, \mathrm{Mg}$ and $\mathrm{Na}$ are required in macronutrient amounts, others occur in trace or ultra trace quantities. $\mathrm{Cu}, \mathrm{Fe}, \mathrm{Ni}, \mathrm{Zn}$, and $\mathrm{Mn}$ are at the top end of this trace scale and play an important role in biological systems. On the other hand, some elements (e.g., $\mathrm{Pb}$ and $\mathrm{Cd}$ ) are non-essential elements and toxic even in trace amounts [1].
The quest for a healthy life style has intensified the consumption of natural products, such as fruit juices. Fruit juices contain vitamins, minerals and easily digestible fruit sugar that are beneficial to our body [2].

Although fruit juices do not contain much nutritional value, they are widely consumed all over the world due to the diversity of flavors and also because of their diet, light and low calorie versions. There are a large variety of potential contaminants in soft drinks (Al, As, Cd, Cr, Cu, 
$\mathrm{Hg}, \mathrm{Pb}, \mathrm{Se}$ and others). Therefore, the mineral composition of such beverages needs to be investigated [3].

The determination of minerals in fruit and their juices has been carried out using several analytical techniques, each with its advantages and disadvantages. McHard et al in their study evaluated four spectrometric methods for orange juice analysis: flame atomic spectrometry (FAAS), direct current plasma atomic emission spectrometry (DCP-AES), inductively coupled plasma atomic emission spectrometry (ICP-AES) and atomic fluorescence spectrometry (AFS) [4]. Castro et al used a factorial design in the optimization of a preconcentration procedure to determine copper by FAAS [5]. Graphite furnace atomic absorption spectrometry (GFAAS) was employed by Seruga et al to determine Al in soft drink samples that had been stored for 12 months [6].

Inductively coupled plasma atomic emission spectrometry (ICP-AES) has proved to be a rapid and accurate technique for the determination of minor and major element contents in fruits and fruit juices [7-9]. ICP-MS is another method for the quantitative determination of a range of metals in a variety of fruit juices [10].

The aim of this study is to determine the amount of major and minor elements in two types of fruit juices, clear and cloudy, obtained from various kinds of fruits (cherry, black cranberry, black grape, blueberry, peach, apple, strawberry and apricot), in Niš markets in Serbia, as basis for evaluating their possible effects on the health of consumers consumption.

\section{EXPERIMENTAL}

\section{Reagents}

ICP multi-element standard solution (Ultra Scientific, USA) with a concentration of $20.0 \pm$ $0.1 \mathrm{mg} / \mathrm{L}$ was used as stock solution for calibration. Nitric acid (Merck, Darmstad) and hydrochloric acid (Merck, Darmstad) were used for complete mineralization of analyzed samples.

The plastic containers used for storing the samples were cleaned to avoid contamination of the samples with traces of any metal. Containers were treated with $5 \%$ nitric acid and washed with ultra-pure water $0.05 \mu \mathrm{S} / \mathrm{cm}$ (MicroMed high purity water system, TKA Wasseraufbereitungssysteme $\mathrm{GmbH}$ ).

\section{Instrumentation}

All analysis were carried out on an iCAP 6000 inductively coupled plasma optical emission spectrometer (Thermo Scientific, Cambridge, United Kingdom) with an Echelle optical design and a charge injection device (CID) solid state detector. The instrument was operated under the conditions shown in Table 1.

Table 1: Operational parameters for ICP-OES measurement

\begin{tabular}{ll}
\hline Parameter & Value \\
\hline Flush pump rate & $100 \mathrm{rpm}$ \\
Analysis pump rate & $50 \mathrm{rpm}$ \\
RF power & $1150 \mathrm{~W}$ \\
Nebulizer gas & $0.7 \mathrm{~L} / \mathrm{min}$ \\
Coolant gas flow & $12 \mathrm{~L} / \mathrm{min}$ \\
Auxiliary gas flow & $0.5 \mathrm{~L} / \mathrm{min}$ \\
Plasma view & Axial \\
\hline
\end{tabular}

\section{Sample preparation}

In this study, two types of commercial fruit juices (clear and cloudy) of 10 different most frequently consumed brands were obtained from different markets in city of Niš, Serbia (Table 2). A total of 24 juice samples were analyzed in this study.

Table 2: Types of tested fruit juices samples

\begin{tabular}{ll}
\hline Clear & Cloudy \\
\hline Cherry-Ac & Peach and Apple-Bpa \\
Black cranberry-Abc & Strawberry and Apple-Bsa \\
Black grape-Abg & Peach-Bp \\
Blueberry-Ab & Strawberry-Bs \\
& $\begin{array}{l}\text { Apricot and Apple-Baa } \\
\text { Multivitamine-Bmv }\end{array}$ \\
\hline
\end{tabular}

Samples of fruit juices were prepared for metal determination by dry digestion method [11]. Each fruit juice sample $(20 \mathrm{~mL})$ was transferred into the glowing pot and heated at $100{ }^{\circ} \mathrm{C}$ in a sand bath. After evaporation, the sample was heated in a furnace at $600{ }^{\circ} \mathrm{C}$ for $12 \mathrm{~h}$. In order to complete mineralization of the samples, $65 \%$ $\mathrm{HNO}_{3}$ was added, heated to dry and then returned into the furnace for another $10 \mathrm{~h}$. The ash obtained was digested in $36 \% \mathrm{HCl}$ and filtered through a Whatman no. 541 tape into a $50 \mathrm{~mL}$ flask.

\section{Data analysis}

All measurements were carried out in triplicate, and presented as mean \pm standard deviation (SD). Significant differences among mean values, where applicable, were determined by one-way analysis of variance (ANOVA). A $p$ value $<0.05$ was considered statistically significant. For all statistical calculations 
statistical package of software SPSS 20 was used [12].

\section{RESULTS}

For the purpose of validation of the method, the limit of detection $(L O D=3 \times S D / m)$, the limit of quantification $(\mathrm{LOQ}=10 \times \mathrm{SD} / \mathrm{m})$ for each metal were computed, where SD is the standard deviation of reagent blank and $m$ is the slope of the calibration graph; emission wavelength and correlation coefficient of the calibration curve for each metal were also determined and are shown in Table 3.

Table 3: Emission wavelength, LOD, LOQ and correlation coefficient of the calibration for each mineral determination

\begin{tabular}{lcccc}
\hline Element & Wavelength $(\mathbf{n m})$ & $\begin{array}{c}\text { Correlation } \\
\text { coefficient }\end{array}$ & LOD $\left(\boldsymbol{\mu g m L} \mathbf{~}^{-1}\right)$ & LOQ $\left(\boldsymbol{\mu g m L} \mathbf{~}^{-1}\right)$ \\
$\mathrm{Al}$ & 396.152 & 0.999911 & 0.105856 & 0.352854 \\
$\mathrm{~B}$ & 208.959 & 0.999088 & 0.339082 & 1.130273 \\
$\mathrm{Ba}$ & 493.409 & 0.998137 & 0.484891 & 1.616302 \\
$\mathrm{Be}$ & 313.107 & 0.997128 & 0.602485 & 2.008285 \\
$\mathrm{Ca}$ & 396.847 & 0.995322 & 0.770020 & 2.566733 \\
$\mathrm{Co}$ & 230.786 & 0.999731 & 0.082623 & 0.275512 \\
$\mathrm{Cd}$ & 228.802 & 0.999144 & 0.328490 & 1.094967 \\
$\mathrm{Cr}$ & 357.869 & 0.999567 & 0.233531 & 0.778437 \\
$\mathrm{Cu}$ & 324.754 & 0.999920 & 0.100650 & 0.335499 \\
$\mathrm{Fe}$ & 238.204 & 0.997528 & 0.558845 & 1.862817 \\
$\mathrm{~K}$ & 766.490 & 0.999891 & 0.262518 & 0.875059 \\
$\mathrm{Mg}$ & 280.270 & 0.996661 & 0.649883 & 2.166278 \\
$\mathrm{Mn}$ & 260.569 & 0.997829 & 0.523595 & 1.745317 \\
$\mathrm{Na}$ & 588.995 & 0.999975 & 0.055571 & 0.185237 \\
$\mathrm{Ni}$ & 341.476 & 0.999949 & 0.080132 & 0.267107 \\
$\mathrm{Si}$ & 288.158 & 0.998632 & 0.928667 & 3.095556 \\
$\mathrm{Zn}$ & 213.856 & 0.998799 & 0.389066 & 1.296888 \\
\hline
\end{tabular}

The highest content of macro-element present in all samples of clear fruit juices was potassium and it ranged from 85.35 to $192.2 \mu \mathrm{g} / \mathrm{g}$. Black cranberry juice showed the highest content of $\mathrm{K}$ while the lowest content was detected in blueberry juice. The content of potassium was nearly the same in all the juice brands (Table 4).

In cloudy fruit juices, $\mathrm{K}$ content ranged from 54.4 to $230.9 \mu \mathrm{g} / \mathrm{g}$ (Table 5). The highest content of this macro-element was in multivitamin juice while the lowest content was in strawberry juice. There was statistically significant difference between clear and cloudy fruit juices $(p<0.05)$. Iron was the most prominent essential element (Tables 4 and 5). The highest content of iron was obtained for black grape juice $(5.9 \mu \mathrm{g} / \mathrm{g})$. The content of other essential trace elements followed the descending order $\mathrm{Cu}>\mathrm{Zn}>\mathrm{Ni}(p<$ 0.05).

Cadmium, which is a toxic element, was detected in all the tested fruit juices. The content of this heavy element was higher in clear juices than in cloudy fruit juices; the content ranged from 0.0327 to $0.1212 \mu \mathrm{g} / \mathrm{g}$ and 0.0137 to 0.0803 $\mu \mathrm{g} / \mathrm{g}$, respectively (Tables 4 and 5 ).

The content of aluminum ranged from 38.83 to $91.01 \mu \mathrm{g} / \mathrm{g}$ in clear fruit juices and 5.328 to 47.32 $\mu \mathrm{g} / \mathrm{g}$ in cloudy fruit juices. The results indicate that black grape had the highest content of aluminum $(p<0.05)$.

\section{DISCUSSION}

Konić-Ristić et al had also shown that the content of potassium was highest in different berry juices compared to other macro-elements $(\mathrm{Ca}, \mathrm{Mg}$ and $\mathrm{Na)}$ [13].

Potassium is the most abundant intracellular ion, and it is essential for membrane transport, energy metabolism and normal functioning of cells. Potassium is found naturally in the fruit in the form of potassium salts of tartaric acid. The higher content of $\mathrm{K}$ that were detected in fruit juices may be due to that during the production of this products many potassium compounds are added as sweeteners (acesulfame K) or preservatives (E212-potassium benzoate, potassium sorbate-E201, potassium bisulfiteE228), which lead to an increase in the content of this macro element in fruit juices over the baseline which derived from the fruit [14]. Our study showed statistical significance difference in content of $\mathrm{K}$ for tasted fruit juices, that indicate that all fruit juice had different content of this element. In regard of this finding, every type of fruit juices can have different nutritional value for 
Table 4: Content $(\mu \mathrm{g} / \mathrm{g})$ of trace elements in the analyzed samples of clear fruit juices (mean $\pm \mathrm{SD}$ )

\begin{tabular}{|c|c|c|c|c|c|c|}
\hline \multirow{2}{*}{ Element } & \multicolumn{3}{|l|}{ Cherry } & \multicolumn{3}{|l|}{ Black cranberry } \\
\hline & Ac1 & Ac2 & Ac3 & Abc1 & Abc2 & Abc3 \\
\hline Al & $55.15 \pm 0.15$ & $38.83 \pm 0.05$ & $44.83 \pm 0.20$ & $57.38 \pm 0.05$ & $39.12 \pm 0.14$ & $46.17 \pm 0.22$ \\
\hline B & $2.845 \pm 0.023$ & $2.545 \pm 0.023$ & $3.583 \pm 0.022$ & $5.263 \pm 0.015$ & $4.171 \pm 0.021$ & $4.781 \pm 0.019$ \\
\hline $\mathrm{Ba}$ & $1.045 \pm 0.003$ & $1.247 \pm 0.008$ & $0.252^{\star} \pm 0.002$ & $0.758 \pm 0.006$ & $1.176 \pm 0.002$ & $0.991 \pm 0.007$ \\
\hline $\mathrm{Be}$ & $2.721 \pm 0.155$ & $3.103 \pm 0.058$ & $3.487 \pm 0.181$ & $3.577 \pm 0.073$ & $3.913 \pm 0.082$ & $2.906 \pm 0.076$ \\
\hline $\mathrm{Ca}$ & $42.83 \pm 0.45$ & $48.63 \pm 0.45$ & $50.45 \pm 0.43$ & $42.78 \pm 1.02$ & $46.17 \pm 0.52$ & $44.69 \pm 0.94$ \\
\hline Cd & $0.0571 \pm 0.0017$ & $0.0884 \pm 0.0052$ & $0.0661 \pm 0.0017$ & $0.0621 \pm 0.0036$ & $0.1212 \pm 0.0018$ & $0.0761 \pm 0.0030$ \\
\hline Co & $0.021^{*} \pm 0.002$ & $0.012^{*} \pm 0.001$ & $0.021^{*} \pm 0.003$ & $0.018^{*} \pm 0.004$ & $0.016^{*} \pm 0.001$ & $0.011^{*} \pm 0.002$ \\
\hline $\mathrm{Cr}$ & $0.2462 \pm 0.0062$ & $0.1877 \pm 0.0059$ & $0.3615 \pm 0.0041$ & $0.2379 \pm 0.0045$ & $0.1712 \pm 0.0071$ & $0.1983 \pm 0.0023$ \\
\hline $\mathrm{Cu}$ & $0.2841 \pm 0.0032$ & $0.4654 \pm 0.0062$ & $0.6683 \pm 0.0071$ & $0.5292 \pm 0.0032$ & $0.3185 \pm 0.0026$ & $0.7441 \pm 0.0062$ \\
\hline $\mathrm{Fe}$ & $5.145 \pm 0.013$ & $4.325 \pm 0.095$ & $3.745 \pm 0.032$ & $5.515 \pm 0.045$ & $4.782 \pm 0.017$ & $5.223 \pm 0.024$ \\
\hline $\mathbf{K}$ & $157.2 \pm 1.5$ & $175.7 \pm 3.3$ & $187.0 \pm 0.8$ & $181.5 \pm 1.3$ & $192.4 \pm 1.5$ & $189.9 \pm 0.9$ \\
\hline Mg & $39.88 \pm 0.15$ & $34.43 \pm 0.02$ & $55.25 \pm 0.05$ & $36.83 \pm 0.27$ & $33.17 \pm 0.31$ & $49.42 \pm 0.51$ \\
\hline$M n$ & $0.2722^{*} \pm 0.0032$ & $0.2675^{*} \pm 0.0042$ & $0.5941 \pm 0.0082$ & $0.4092^{*} \pm 0.0043$ & $0.3921^{\star} \pm 0.0031$ & $0.6214 \pm 0.0072$ \\
\hline $\mathrm{Na}$ & $75.80 \pm 0.30$ & $53.33 \pm 0.45$ & $106.1 \pm 0.9$ & $81.43 \pm 0.57$ & $66.27 \pm 0.71$ & $99.46 \pm 0.61$ \\
\hline $\mathbf{N i}$ & $0.0153^{*} \pm 0.0024$ & $0.0501^{*} \pm 0.0042$ & $0.0465^{\star} \pm 0.0105$ & $0.0431^{*} \pm 0.0072$ & $0.0522^{*} \pm 0.0081$ & $0.0223^{*} \pm 0.0021$ \\
\hline $\mathbf{S i}$ & $87.65 \pm 0.20$ & $71.98 \pm 0.20$ & $83.75 \pm 0.40$ & $88.53 \pm 0.22$ & $92.14 \pm 0.33$ & $79.49 \pm 0.41$ \\
\hline $\mathrm{Zn}$ & $0.1583^{*} \pm 0.0061$ & $0.3201 \pm 0.0042$ & $0.3822 \pm 0.0051$ & $0.3842 \pm 0.0023$ & $0.3923 \pm 0.0051$ & $0.4212 \pm 0.0063$ \\
\hline \multicolumn{4}{|c|}{ Black grape } & \multicolumn{3}{|l|}{ Blueberry } \\
\hline \multirow[t]{2}{*}{ Element } & \multicolumn{3}{|l|}{ Abg2 } & Ab1 & Ab2 & Ab3 \\
\hline & $86.12 \pm 0.41$ & \multicolumn{2}{|c|}{$91.01 \pm 0.13$} & $79.30 \pm 0.35$ & $88.76 \pm 0.74$ & $76.13 \pm 0.22$ \\
\hline Al & $4.238 \pm 0.021$ & \multicolumn{2}{|c|}{$5.174 \pm 0.048$} & $17.27 \pm 0.09$ & $13.18 \pm 0.12$ & $15.10 \pm 0.09$ \\
\hline B & $1.358 \pm 0.008$ & \multicolumn{2}{|c|}{$1.566 \pm 0.004$} & $0.439 \pm 0.007$ & $0.266 \pm 0.009$ & $0.467 \pm 0.005$ \\
\hline $\mathrm{Ba}$ & $2.113 \pm 0.067$ & \multicolumn{2}{|c|}{$2.998 \pm 0.094$} & $3.212 \pm 0.037$ & $3.559 \pm 0.144$ & $3.736 \pm 0.099$ \\
\hline $\mathrm{Be}$ & $49.36 \pm 0.82$ & \multicolumn{2}{|c|}{$55.84 \pm 1.02$} & $44.20 \pm 0.90$ & $45.57 \pm 0.21$ & $39.12 \pm 0.13$ \\
\hline $\mathrm{Ca}$ & $0.0722 \pm 0.0019$ & \multicolumn{2}{|c|}{$0.0935 \pm 0.0057$} & $0.0327 \pm 0.0014$ & $0.0458 \pm 0.0012$ & $0.0662 \pm 0.0066$ \\
\hline Cd & $0.022^{*} \pm 0.004$ & \multicolumn{2}{|c|}{$0.018^{\star} \pm 0.003$} & $0.052^{*} \pm 0.009$ & $0.044^{*} \pm 0.008$ & $0.038^{*} \pm 0.007$ \\
\hline Co & $0.3296 \pm 0.0019$ & \multicolumn{2}{|c|}{$0.1967 \pm 0.0037$} & $0.1064 \pm 0.0046$ & $0.0935 \pm 0.0064$ & $0.0798 \pm 0.0012$ \\
\hline $\mathrm{Cr}$ & $0.3211 \pm 0.0081$ & \multicolumn{2}{|c|}{$0.5847 \pm 0.0122$} & $0.7221 \pm 0.0012$ & $0.6646 \pm 0.0023$ & $0.8475 \pm 0.0044$ \\
\hline $\mathrm{Cu}$ & $5.299 \pm 0.044$ & \multicolumn{2}{|c|}{$5.911 \pm 0.058$} & $2.237 \pm 0.028$ & $4.181 \pm 0.051$ & $3.275 \pm 0.032$ \\
\hline $\mathrm{Fe}$ & $144.2 \pm 1.8$ & $156.8 \pm 1$ & & $85.35 \pm 0.90$ & $92.17 \pm 1.4$ & $101.87 \pm 1.7$ \\
\hline $\mathbf{K}$ & $32.17 \pm 0.24$ & $57.24 \pm 0$ & & $51.58 \pm 0.50$ & $49.98 \pm 0.27$ & $55.41 \pm 0.74$ \\
\hline $\mathbf{M g}$ & $0.2841^{*} \pm 0.0121$ & $0.2992^{*}$ & 0.0181 & $2.2474 \pm 0.0283$ & $1.7442 \pm 0.0321$ & $1.4831 \pm 0.0442$ \\
\hline Mn & $88.21 \pm 0.74$ & $75.16 \pm 0$ & & $107.6 \pm 0.40$ & $124.9 \pm 0.91$ & $113.2 \pm 0.71$ \\
\hline $\mathrm{Na}$ & $0.0413^{*} \pm 0.0083$ & $0.0391^{*}$ & 0.0091 & $0.2193 \pm 0.0102$ & $0.3275 \pm 0.0121$ & $0.2562 \pm 0.0091$ \\
\hline $\mathrm{Ni}$ & $101.4 \pm 0.96$ & $114.7 \pm 1$ & & $122.6 \pm 0.7$ & $139.4 \pm 0.9$ & $110.6 \pm 0.8$ \\
\hline Si & $0.3221 \pm 0.0072$ & $0.2552 \pm$ & 0.0071 & $0.4144 \pm 0.0104$ & $0.5222 \pm 0.0112$ & $0.4783 \pm 0.0251$ \\
\hline
\end{tabular}

"Detected content was < LOD for this element 
Table 5: Content $(\mu \mathrm{g} / \mathrm{g})$ of trace elements in the analyzed samples of cloudy fruit juices (mean $\pm \mathrm{SD}$ )

\begin{tabular}{|c|c|c|c|c|c|c|c|}
\hline \multirow[t]{2}{*}{ Element } & \multicolumn{3}{|c|}{ Peach and apple } & \multicolumn{3}{|c|}{ Strawberry and apple } & \multirow{2}{*}{$\begin{array}{l}\text { Peach } \\
\text { Bp2 }\end{array}$} \\
\hline & Bpa1 & Bpa2 & Bsa1 & \multicolumn{2}{|c|}{ Bsa2 } & Bp1 & \\
\hline Al & $38.52 \pm 0.25$ & $16.08 \pm 0.27$ & $47.32 \pm 0.07$ & \multicolumn{2}{|c|}{$16.87 \pm 0.09$} & $14.55 \pm 0.05$ & $22.38 \pm 0.29$ \\
\hline B & $1.145 \pm 0.061$ & $1.232 \pm 0.012$ & $1.103 \pm 0.029$ & \multicolumn{2}{|c|}{$1.021 \pm 0.023$} & $0.7928 \pm 0.0173$ & $0.6231 \pm 0.0072$ \\
\hline $\mathrm{Ba}$ & $0.5311 \pm 0.0064$ & $0.3963 \pm 0.0078$ & $0.7273 \pm 0.0032$ & \multicolumn{2}{|c|}{$0.5080 \pm 0.0032$} & $0.3732 \pm 0.0054$ & $0.4873 \pm 0.0061$ \\
\hline $\mathrm{Be}$ & $3.503 \pm 0.193$ & $3.089 \pm 0.082$ & $3.388 \pm 0.083$ & \multicolumn{2}{|c|}{$3.409 \pm 0.055$} & $3.534 \pm 0.171$ & $3.128 \pm 0.089$ \\
\hline $\mathrm{Ca}$ & $74.90 \pm 0.46$ & $35.84 \pm 0.43$ & $73.89 \pm 1.05$ & \multicolumn{2}{|c|}{$45.53 \pm 0.32$} & $38.59 \pm 0.94$ & $42.29 \pm 0.52$ \\
\hline Cd & $0.0624 \pm 0.0012$ & $0.0782 \pm 0.0032$ & $0.0798 \pm 0.0022$ & 0.0 & $803 \pm 0.0028 \quad 0$ & $0.0471 \pm 0.0087$ & $0.0281 \pm 0.0017$ \\
\hline Co & $0.034^{*} \pm 0.007$ & $0.028^{*} \pm 0.002$ & $0.022^{*} \pm 0.002$ & 0.0 & $13^{*} \pm 0.001$ & $0.017^{*} \pm 0.007$ & $0.019^{*} \pm 0.002$ \\
\hline $\mathrm{Cr}$ & $0.1360 \pm 0.0053$ & $0.1419 \pm 0.0049$ & $0.1355 \pm 0.0035$ & 0.1 & $406 \pm 0.0057 \quad 0$ & $0.3765 \pm 0.0032$ & $0.2214 \pm 0.0219$ \\
\hline $\mathrm{Cu}$ & $0.6120 \pm 0.0046$ & $0.2282 \pm 0.0062$ & $0.7753 \pm 0.0147$ & 0.2 & $079 \pm 0.0392$ & $1.363 \pm 0.014$ & $0.9276 \pm 0.0221$ \\
\hline $\mathrm{Fe}$ & $6.237 \pm 0.285$ & $6.223 \pm 0.311$ & $10.05 \pm 0.21$ & 7.1 & $52 \pm 0.167$ & $7.372 \pm 0.328$ & $8.963 \pm 0.428$ \\
\hline $\mathbf{K}$ & $194.4 \pm 0.6$ & $90.55 \pm 0.98$ & $178.9 \pm 0.4$ & 72 & $20 \pm 0.46$ & $185.3 \pm 0.4$ & $164.1 \pm 0.99$ \\
\hline Mg & $25.37 \pm 0.54$ & $27.07 \pm 0.52$ & $31.83 \pm 0.31$ & 28 & $20 \pm 0.31$ & $24.64 \pm 0.46$ & $29.14 \pm 0.51$ \\
\hline Mn & $0.4174 \pm 0.0022$ & $0.1691 \pm 0.0088$ & $0.7851 \pm 0.0018$ & 0.5 & $529 \pm 0.0018 \quad 0$ & $0.3462 \pm 0.0044$ & $0.3875 \pm 0.0021$ \\
\hline $\mathrm{Na}$ & $73.19 \pm 0.43$ & $51.34 \pm 0.72$ & $65.24 \pm 0.32$ & 50 & $16 \pm 3.20$ & $50.58 \pm 0.11$ & $55.32 \pm 0.30$ \\
\hline $\mathrm{Ni}$ & $0.3603 \pm 0.0018$ & $0.1537 \pm 0.0034$ & $0.1946 \pm 0.0022$ & 0.1 & $757 \pm 0.0032 \quad 0$ & $0.3305 \pm 0.0016$ & $0.2684 \pm 0.0011$ \\
\hline Si & $133.6 \pm 1.5$ & $25.49 \pm 1.04$ & $124.3 \pm 1.6$ & 37. & $02 \pm 0.21$ & $19.05 \pm 0.24$ & $44.17 \pm 0.12$ \\
\hline $\mathrm{Zn}$ & $0.8380 \pm 0.0014$ & $0.3108 \pm 0.0020$ & $0.2604 \pm 0.0018$ & 0.2 & $177 \pm 0.0032 \quad 0$ & $0.5359 \pm 0.0016$ & $0.4816 \pm 0.0028$ \\
\hline & Stran & & Apricot and & $\underline{a}$ & & Multivi & \\
\hline Element & Bs1 & Bs2 & Baa1 & & Baa2 & Bmv1 & Bmv2 \\
\hline Al & $6.215 \pm 0.027$ & $5.328 \pm 0.013$ & $10.19 \pm 0.14$ & & $12.24 \pm 0.17$ & $40.89 \pm 0.09$ & $52.14 \pm 0.12$ \\
\hline B & $0.6360 \pm 0.0435$ & $0.5978 \pm 0.0281$ & $0.6989 \pm 0.027$ & & $0.5712 \pm 0.0328$ & $\begin{array}{ll}8 & 0.9509 \pm 0.017\end{array}$ & $75 \quad 1.221 \pm 0.019$ \\
\hline $\mathrm{Ba}$ & $0.4374 \pm 0.0023$ & $0.6112 \pm 0.0031$ & $0.4574 \pm 0.004$ & & $0.3917 \pm 0.0023$ & $\begin{array}{ll}3 & 0.4967 \pm 0.003\end{array}$ & $38 \quad 0.8147 \pm 0.0071$ \\
\hline $\mathrm{Be}$ & $3.645 \pm 0.127$ & $3.251 \pm 0.113$ & $3.047 \pm 0.152$ & & $2.512 \pm 0.099$ & $2.094 \pm 0.192$ & $2.717 \pm 0.117$ \\
\hline $\mathrm{Ca}$ & $44.58 \pm 0.11$ & $39.27 \pm 0.18$ & $38.66 \pm 0.46$ & & $44.15 \pm 0.27$ & $47.79 \pm 0.03$ & $66.17 \pm 0.51$ \\
\hline Cd & $0.0271 \pm 0.0014$ & $0.0228 \pm 0.0011$ & $0.0593 \pm 0.001$ & & $0.0471 \pm 0.0012$ & $2 \quad 0.0137 \pm 0.002$ & $20 \quad 0.0102 \pm 0.0011$ \\
\hline Co & $0.041^{\star} \pm 0.008$ & $0.032^{*} \pm 0.005$ & $0.016^{\star} \pm 0.003$ & & $0.029^{*} \pm 0.006$ & $0.037^{*} \pm 0.002$ & $0.041^{*} \pm 0.004$ \\
\hline $\mathrm{Cr}$ & $0.0974 \pm 0.0050$ & $0.0825 \pm 0.0048$ & $0.1431 \pm 0.003$ & & $0.2218 \pm 0.0017$ & $\begin{array}{ll}7 & 0.0447 \pm 0.002\end{array}$ & $25 \quad 0.0217 \pm 0.0019$ \\
\hline $\mathrm{Cu}$ & $0.1553 \pm 0.0074$ & $0.5214 \pm 0.0092$ & $0.2533 \pm 0.006$ & & $0.2938 \pm 0.0055$ & $5 \quad 0.4064 \pm 0.019$ & $98 \quad 0.6177 \pm 0.0211$ \\
\hline $\mathrm{Fe}$ & $3.555 \pm 0.092$ & $4.228 \pm 0.078$ & $6.380 \pm 0.091$ & & $5.914 \pm 0.078$ & $5.251 \pm 0.096$ & $8.257 \pm 0.099$ \\
\hline $\mathbf{K}$ & $54.40 \pm 0.27$ & $79.28 \pm 0.52$ & $82.35 \pm 0.49$ & & $102.4 \pm 1.02$ & $214.9 \pm 1.1$ & $230.17 \pm 1.2$ \\
\hline Mg & $23.99 \pm 0.19$ & $25.17 \pm 0.20$ & $23.32 \pm 0.44$ & & $27.42 \pm 0.71$ & $68.01 \pm 0.76$ & $75.12 \pm 0.91$ \\
\hline Mn & $0.4916 \pm 0.0049$ & $0.3751 \pm 0.0017$ & $0.0918 \pm 0.001$ & & $0.1216 \pm 0.0072$ & $2 \quad 1.970 \pm 0.070$ & $2.215 \pm 0.052$ \\
\hline $\mathrm{Na}$ & $35.31 \pm 0.29$ & $42.77 \pm 0.22$ & $45.48 \pm 0.20$ & & $53.71 \pm 0.33$ & $68.46 \pm 0.42$ & $77.38 \pm 0.61$ \\
\hline $\mathrm{Ni}$ & $0.1675 \pm 0.0030$ & $0.1601 \pm 0.0022$ & $0.1712 \pm 0.002$ & & $0.2123 \pm 0.0017$ & $\begin{array}{ll}7 & 0.1791 \pm 0.002\end{array}$ & $0.1511 \pm 0.0015$ \\
\hline Si & $12.23 \pm 0.21$ & $25.32 \pm 1.02$ & $33.38 \pm 0.42$ & & $47.15 \pm 0.31$ & $63.07 \pm 0.29$ & $72.44 \pm 0.31$ \\
\hline $\mathrm{Zn}$ & $0.1474 \pm 0.0014$ & $0.2427 \pm 0.0048$ & $0.2808 \pm 0.001$ & & $0.3115 \pm 0.0033$ & $\begin{array}{ll}3 & 0.4960 \pm 0.001\end{array}$ & $16 \quad 0.6177 \pm 0.0022$ \\
\hline
\end{tabular}


human diet, according to the content of potassium.

The recommended daily dose of potassium, according to the Regulations on safety of dietary supplements in the Republic of Serbia, is 2000 $\mathrm{mg}$ [15]. Since the $\mathrm{K}$ content in samples of the fruit juices was about $200 \mathrm{mg} / \mathrm{L}$, it falls below the allowable limits and the juices can be used as an additional source of this macro-element in human nutrition.

Fruit juices contain sodium (the water and added sodium salts such as benzoates, citrates or saccharin), calcium and magnesium (the water and the fruit). Enrichment of juice in these minerals is very simple because their compounds (salts) easily soluble but on the other hand, excessive addition of these compounds can lead to salty or bitter taste of juice, and the laxative effect [14].

The results of this study are in accordance with findings of Jablani et al. where the content of iron was also higher than copper and zinc in some juices that are commercially available in Pakistan [16].

It is known that iron is required for the activity of certain enzymes involved in energy production and about $10 \%$ of the body pool of iron is used in this way. Iron deficiency leads to microcytic, hypochromic anemia and the symptoms include fatigue, weakness, pallor, dyspnoea on exertion and palpitations. Gastrointestinal symptoms are also fairly common and fingernails may become lusterless, brittle, flattened and spoon-shaped [17].

The content of essential trace elements showed statistical significance difference in samples of all tasted fruit juices, that mean that fruit juices had different content of this important micronutrients. From the results of this study, all the tested fruit juices can serve as additional sources of this essential trace element in daily human nutrition.

Although the content of cadmium was very low compare to other detected elements, this metal can be deposited in bones, liver and kidneys, and due to its cumulative effect, the function of these organs can be impaired [18].

The content of cadmium in tasted fruit juices is below permitted limits, but it should be addressed that regulations in Serbia that should prescribed the maximal allow content of this heavy metal in fruit juices and other beverages, are out of date. They must be as soon as it possible to be updated, and also coordinated with some European and World regulations, duo to toxic effect of cadmium.

Coco et al also detected the presence of cadmium in apple and pear fruit juices. In their study, the content of cadmium ranged from 2.1 to $3 \mathrm{ng} / \mathrm{g}$ in pear fruit juices and 2.0 to $2.9 \mathrm{ng} / \mathrm{g}$ in samples of apple fruit juices. They concluded that even if the concentrations of this metal in beverages are normally very low, a significant contribution to the increase of the metal quantity assumed by man may derive, owing to the potential great consumption of this kind of beverages [19].

Aluminum content was higher than those of the other trace metals. Clear fruit juices showed much higher content of Al than samples of cloudy fruit juices. Zadeh and Sadeghi, in their work, showed that its content in grape juice was higher than those of other fruit juices [20], a finding which is in accordance with our study. Aluminum is a metal with no nutritional value but to which humans are frequently exposed. The metal may enter the human body by mouth, intravenous infusion as well as by environment, including drinking water, food and pharmacological products. This element has been implicated as a causative factor in several clinical and neuropathological diseases, such as Alzheimer's, Parkinson's, Parkinson-Guam's disease, amyotrophic lateral sclerosis, diabetes and cancer [21].

Total aluminium content in soft drinks includes aluminium which is present naturally in water, aluminium from $\mathrm{Al}$-containing food additives and colors and that which arises from contact with Almade containers $[22,23]$. The packaging material for all tested fruit juces is typically a brick-shaped carton synonymous with the name of TetraPak and TetraBriks, and it is made from layers of paper, plastic (polyethylene) and aluminium foil. Al foil is a solid metal with negligible vapour pressure and hence the idea that $\mathrm{Al}$ by itself should start migrating through the polymer is ruled out. It is well established that several components in orange juice migrate into polymers [24]. Aluminium surfaces can deteriorate whenever they come into contact with salty, acidic, or even neutral aqueous media [25]. Because of those corrosive effects, Al can migrate to the fruit juice and its content may be elevated in the products. Aluminum does have any nutritive value in human diet, so its high content is not desirable. Al present in tested fruit 
juices in this study, may be due to the production process and packaging.

\section{CONCLUSION}

Fruit juices are a good dietary source of macroand micro-nutrient elements. Thus, its analysis is important for nutritional interests. All the tested juices showed that they are of nutritional value to human health and that they can be used as an additional source of macro- and micro-elements. However, the content of metals varied according to the fruit juice type (clear and cloudy) and species of fruit. The presence of aluminum and cadmium, which have no nutritional value and can be toxic can be treated as potential contaminants in this type of beverages. The content of this two metals are below levels permitted by national regulations, but due to their potential harmful effect to human health, it is necessary to monitor their presence in commercial fruit juices. ICP-OES technique used in this study was found to be accurate, rapid and reliable for major and minor elements determination in samples of fruit juices.

\section{ACKNOWLEDGEMENT}

This research was supported by grant nos. 172047 and 33034 of the Ministry of Education and Science of the Republic of Serbia. The authors are grateful for this support.

\section{REFERENCES}

1. Juranović I, Zeiner $M$, Kröppl $M$, Stringeder $G$. Comparison of sample preparation methods for the ICP-AES determination of minor and major elements in clarified apple juices. Microchem $J$ 2011; 99: 364-369.

2. Froes RES, Neto WB, Couto e Silva NO, Naveira RLP, Nascentes CC, Borba da Silva JB. Multivariate optimization by exploratory analysis applied to the determination of microelements in fruit juice by inductively coupled plasma optical emission spectrometry. Spectrochim Acta B 2009; 64: 619622.

3. Froes RES, Neto WB, Naveira RLP, Silva NC, Nascentes CC, Borba da Silva JB. Exploratory analysis and inductively coupled plasma optical emission spectrometry (ICP OES) applied in the determination of metals in soft drinks. Microchem $J$ 2009; 92: 68-72.

4. McHard JA, Foulk SJ, Nikdel S, Ullman AH, Pollard BD, Winefordner JD. Comparison study of four atomic spectrometric methods for the determination of metallic constituents in orange juice. Anal Chem 1979; 51: 1613-1616.

5. Castro MTPO, Baccan N. Application of factorial design in optimization of preconcentration procedure for copper determination in soft drink by flame atomic absorption spectrometry. Talanta 2005; 65: 12641269.

6. Šeruga M, Grgić J, Mandić M. Aluminium content of soft drinks from aluminium cans. $Z$ Lebensm Unters $F A$ 1994; 198: 313-316.
7. Zeiner $M$, Cindrić IJ, Kröppl $M$, Stingeder $G$ Determination of copper in clarified apple juices. $J$ Agr Food Chem 2010; 58(6): 3617-3620.

8. Simpkins WA, Louie H, Wu M, Harrison M, Goldberg D. Trace elements in Australian orange juice and other products. Food Chem 2000; 71: 423-433.

9. Ferreira EC, Rodrigues SHBG, Ferreira MMC, Nobrega $J A$, Nogueira ARA. Exploratory analysis of inorganic contents in grape juices and soft drinks. Eclet Quim 2002; 27: 77-90.

10. Tormen L, Torres DP, Dittert IM, Araújo RGO, Frescura $V L A$, Curtius AJ. Rapid assessment of metal contamination in commercial fruit juices by inductively coupled mass spectrometry after a simple dilution. J Food Compos Anal 2011; 24(1): 95-102.

11. Somenath M. Sample Preparation Techniques in Analytical Chemistry. John Wiley \& Sons Inc; 2003. pp. 227.

12. Miller JN, Miller JC. Statistics and Chemometrics for Analytical Chemistry. Pearson Education Ltt., England; 2005

13. Ristić AK, Šavikin K, Zdunić G, Janković T, Juranic Z, Menković N, Stanković I. Biological activity and chemical composition of different berry juices. Food Chem 2011; 125: 1412-1417.

14. Ashurst PR. Chemistry and Technology of Soft Drinks and Fruit Juices, 2nd edition. Wiley-Blackwell; 2005; Pp 61-120.

15. Serbian Regulations (2010). Safety of dietary supplements, Vol. 45.

16. Jalbani N, Ahmed F, Kazi TG, Rashid U, Munshi AB, Kandhro A. Determination of essential elements $(\mathrm{Cu}, \mathrm{Fe}$ and $\mathrm{Zn})$ in juices of commercially available in Pakistan. Food Chem Toxicol 2010; 48: 27372740.

17. Velimirović DS, Mitić SS, Tošić $S B$, Pavlović AN, Stojković $M D$, Determination of the content of some trace elements in particular samples of grains, flours and breads by ICP-OES. Oxid Commun 2012; 35(1): 160-171.

18. Kaličanin $B$, Velimirović $D$. Potentiometric stripping analysis of zinc, cadmium and lead in tobacco leaves (Nicotiana tabacum L.) and soil samples. Int J Electrochem Sci 2012; 7: 313-323.

19. Coco FL, Monotti P, Cozzi F, Adami G. Determination of cadmium and lead in fruit juices by stripping chronopotentiometry and comparison of two sample pretreatment procedures. Food Control 2006; 17(12): 966-970.

20. Zadeh HA, Sadeghi GH. Combination of ionic liquidbased dispersive liquid-liquid micro-extraction with stopped-flow spectrofluorometry for the preconcentration and determination of aluminum in natural waters, fruit juice and food samples. Talanta, 2010; 81(3): 778-785.

21. Polizzi S, Pira E, Ferrara M, Bugiani M, Papaleo A, Albera R, Palmi S. Neurotoxic effects of aluminium among foundry workers and Alzheimer's disease. NeuroToxicology 2002; 23(6): 761-774.

22. Pennington JAT, Jones JW. Aluminium in health: $A$ critical review. New York; 1989

23. Massey RC, Taylor D. Aluminium in food and the environment. Royal Society of Chemistry, London; 1991.

24. Rodushkin I, Magnusson A. Aluminium migration to orange juice in laminated paperboard packages. $J$ Food Compos Anal 2005; Volume 18(5): 365-374.

25. Gramiccioni L, Ingrao G, Milana MR, Santaroni $P$, Tomassi G.Aluminium levels in Italian diets and in selected food from aluminium utensils. Food Addit Contam, 1996: 13: 767-774. 